\title{
Aging of Skeletal Muscle Fibers
}

\author{
Natasa Miljkovic, MD, $\mathrm{PhD}^{1}$, Jae-Young Lim, $\mathrm{MD}, \mathrm{PhD}^{2}$, \\ Iva Miljkovic, $\mathrm{MD}, \mathrm{PhD}^{3}$, Walter R. Frontera, $\mathrm{MD}, \mathrm{PhD}^{1,4}$

\begin{abstract}
${ }^{1}$ Department of Physical Medicine and Rehabilitation, Vanderbilt University School of Medicine, Nashville, TN, USA;
${ }^{2}$ Department of Rehabilitation Medicine, Seoul National University College of Medicine, Seoul, Korea;

${ }^{3}$ Department of Epidemiology, Graduate School of Public Health, University of Pittsburgh, Pittsburgh, PA, USA;
\end{abstract} \\ ${ }^{4}$ Department of Physiology, University of Puerto Rico School of Medicine, San Juan, Puerto Rico
}

\begin{abstract}
Aging has become an important topic for scientific research because life expectancy and the number of men and women in older age groups have increased dramatically in the last century. This is true in most countries of the world including the Republic of Korea and the United States. From a rehabilitation perspective, the most important associated issue is a progressive decline in functional capacity and independence. Sarcopenia is partly responsible for this decline. Many changes underlying the loss of muscle mass and force-generating capacity of skeletal muscle can be understood at the cellular and molecular levels. Muscle size and architecture are both altered with advanced adult age. Further, changes in myofibers include impairments in several physiological domains including muscle fiber activation, excitation-contraction coupling, actin-myosin cross-bridge interaction, energy production, and repair and regeneration. A thorough understanding of these alterations can lead to the design of improved preventative and rehabilitative interventions, such as personalized exercise training programs.
\end{abstract}

Keywords Elderly, Sarcopenia, Myofilament

\section{INTRODUCTION}

\section{Aging demographics}

By 2050, the world's population over 60 years will double from about $11 \%$ to $22 \%$ and there will be 2 billion people aged 60 or older living on this planet. Approxi-

Received March 13, 2015; Accepted March 26, 2015

Corresponding author: Walter R. Frontera

Department of Physical Medicine and Rehabilitation, Vanderbilt University Medical Center, Suite 1318, 2201 Children's Way, Nashville, TN 37212, USA

Tel: +1-615-322-7574, Fax: +1-615-327-9289, E-mail: walter.frontera@ vanderbilt.edu

(c) This is an open-access article distributed under the terms of the Creative Commons Attribution Non-Commercial License (http://creativecommons. org/licenses/by-nc/3.0) which permits unrestricted noncommercial use, distribution, and reproduction in any medium, provided the original work is properly cited.

Copyright $\odot 2015$ by Korean Academy of Rehabilitation Medicine mately 400 million will be 80 years or older [1]. Further, by $2050,80 \%$ of older people will live in low- and middleincome countries. This increase in the number of people in older age groups is associated with an increase in life expectancy. For example, in 2012 in South Korea, life expectancy was 81.4 years (84.8 for women and 78.1 for men), which puts South Korea in 14th place among 182 countries in the world (Fig. 1). For comparison purposes it is worth noting that, during the same year, life expectancy in the United States was 78.7 years [2].

The increase in the number of people in older age groups, per se, should not be considered a problem. However, aging is associated with an increased incidence of chronic health conditions and, perhaps more importantly, with an increase prevalence of impairment and disability. Visual and hearing impairments, cognitive de- 
(A)

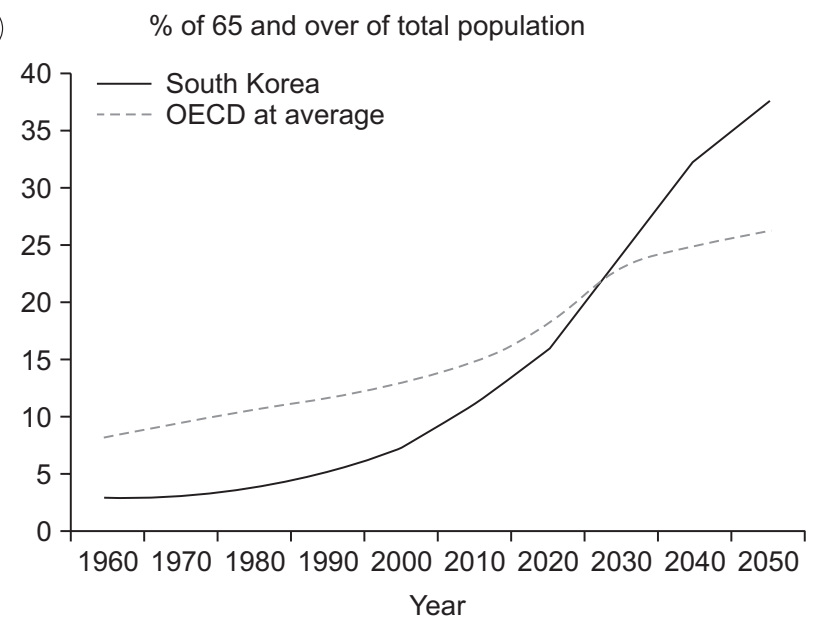

(B)

$\%$ of 65 and over in 2050

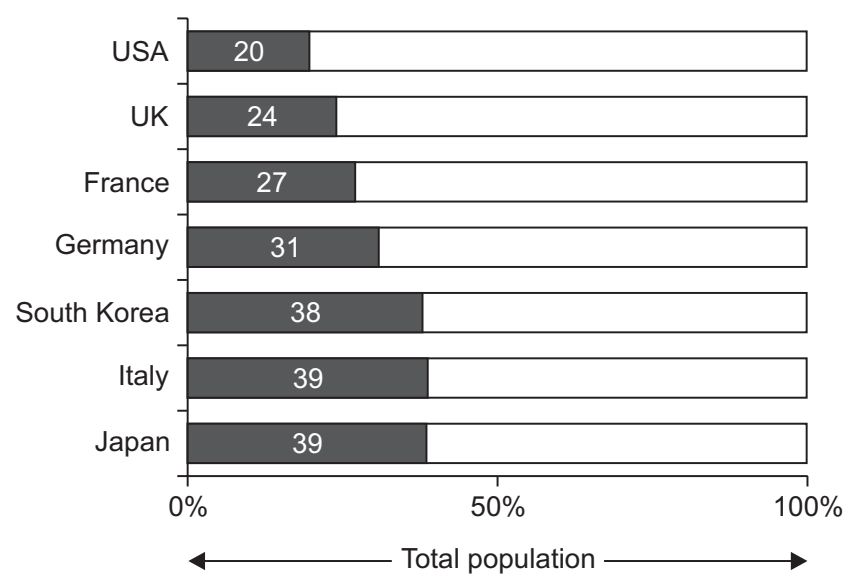

Fig. 1. Percentage of old people in South Korea (A) in comparison with other developed countries (B) from 1960 to 2050 (projected). OECD, Organization for Economic Co-operation and Development.

cline, musculoskeletal disorders, frailty, and sarcopenia all reduce activity and restrict participation in personal, work-associated, and social activities. As a consequence, it has been estimated that, the number of older people requiring long-term care due to loss of functional independence will quadruple by 2050 [1].

\section{Functional changes in elderly}

Aging is associated with changes in body composition (increase in body fat and decreases in muscle and bone mass) which together with a decline in cognitive, visual, and hearing function, sleeping disorders, depression, and increased fatigue lead to a decline in physical function and significantly increases the risk for disability and loss of independence [3].

The prevalence of mobility limitations in elderly is high and is associated with frequent transitions between independent and dependent states. Several studies $[4,5]$ have shown that older men and women transition more frequently from intermittent to continuous mobility limitation, than from no mobility limitation to intermittent mobility limitation. It is however possible to recover mobility after being disabled for 3 months ( $40 \%$ recovery rate) or even for 6 months (30\% recovery rate). These findings suggest the road to disability in elderly is a dynamic process and offers several opportunities to restore function and recover independence [4-7].

Muscle strength is a strong predictor of severe mobility limitation, slow gait speed, increased fall risk, risk of hos- pitalization, and high mortality rate. For example, older adults with low muscle strength have a 2.6 -fold greater risk of severe mobility limitation, 4.3 -fold greater risk for slow gait speed, and 2.1-fold greater risk of mortality compared to older adults with high muscle strength [8]. The loss of muscle strength in elderly cannot be explained only by the characteristic presence of skeletal muscle atrophy. Several recent research studies show that other factors such as changes in central nervous system drive, peripheral nerve dysfunction, alterations in the neuromuscular junction structure and function, fat infiltration, and a number of complex cellular and molecular changes at the level of single muscle fibers impair muscle force generation and power production [9]. In this brief review we will summarize and discuss the cellular and molecular changes at the level of muscle fibers (Fig. 2) that contribute to the above.

\section{DEFINING SARCOPENIA}

One of the most distinctive characteristics of older people is the presence of skeletal muscle weakness and atrophy. The term sarcopenia was used for the first time by Rosenberg $[10,11]$ to refer to the loss of lean body mass with aging. More recently, the European Working Group on Sarcopenia in Older People has expanded the definition and suggested criteria for diagnosis [12] including the presence of muscle weakness (for example handgrip strength), a lower muscle mass (determined by bioelec- 


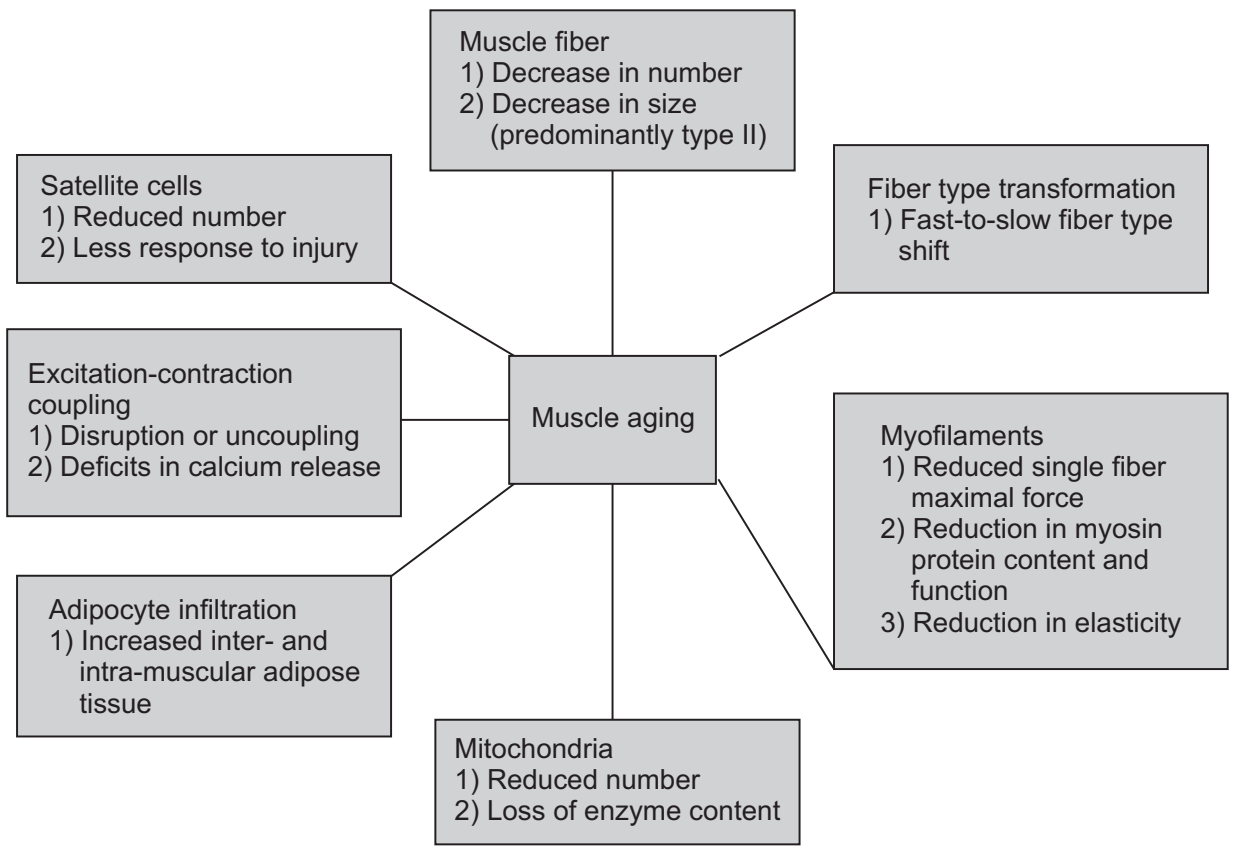

Fig. 2. Cellular and molecular changes at the level of muscle fibers that contribute to muscle aging. trical impedance or dual energy X-ray absorptiometry [DEXA]), and the presence of impaired performance (slow walking speed). The FNIH Sarcopenia Project Group [13] recently recommended normative values for muscle strength and lean body mass as follows: 1) grip strength in men $<26 \mathrm{~kg}$ and in women $<16 \mathrm{~kg}$, or alternate grip strength adjusted for BMI $<1.0$ for men and $<0.56$ for women; and 2) appendicular lean body mass in men $<19.75 \mathrm{~kg}$ and $<15.02 \mathrm{~kg}$ in women, or appendicular lean body mass adjusted for BMI in men $<0.789$ and $<0.512$ in women.

The prevalence of sarcopenia in the older population may range from $4 \%$ to $27 \%$ depending on the gender of the participants and country. In Korea, the prevalence of sarcopenia has been reported to be $11.9 \%$ in women and $12.1 \%$ in men [14]. The loss of muscle mass and strength in older people is of greater magnitude in longitudinal compared to cross-sectional studies [15]. Further, more muscle mass and strength is lost by men compared to women particularly in muscles of the lower limbs $[15,16]$. In fact older women have relatively wellpreserved strength in the muscles of the upper limbs. It must be noted that the loss of strength with advancing age is not a universal phenomenon and some individuals maintain muscle strength after 10 years of follow-up [17]. The explanation for this variability is not clear but it has been suggested that the level of physical activity is a con- tributing factor. In addition to the well-described loss of force sarcopenia is also associated with the loss of muscle power (forcexvelocity), particularly in older people with mobility limitations [18]. Power correlates very well with function and its loss is a good predictor of impaired mobility and falls.

\section{SATELLITE CELLS}

The function of satellite cells in normal skeletal muscle is to maintain the skeletal muscle homeostasis and enable skeletal muscle regeneration. These muscle-specific Pax7-expressing adult stem cells are normally quiescent, but when stimulated by damage or stress, they become activated and enter the cell cycle to either form new muscle fibers or self-renew and replenish the satellite cell pool, that will be used in the future [19-21].

At the level of the individual muscle fiber, sarcopenia may be associated with a reduced number of satellite cells; especially those associated with fibers expressing type II (fast) myosin heavy chain [22]. This is relevant because the majority of the motor unit and fibers lost with advanced adult age are type II. Moreover, the satellite cell activation in response to muscle damage is blunted in older adult men. This phenomenon is mediated by interleukin-6 which is thought to be a positive regulator of satellite cells proliferation and is transiently increased 
after acute exercise-induced trauma [23]. With aging, interleukin- 6 becomes chronically elevated and promotes muscle catabolism most likely via suppressors of cytokine signaling proteins. These events reduce the efficacy of anabolic signaling pathways such as insulin-like growth factor 1 (IGF-1).

\section{MUSCLE FIBER SIZE, STRENGTH, AND POWER}

Normal adult muscle fiber size is reached between the ages 12 and 15 years. In normal muscle, there is less than $12 \%$ difference in the largest mean fiber diameter between all three muscle fiber types [24]. Both type I and type II ( $\mathrm{a}$ and $\mathrm{x}$ ) adult muscle fibers are larger in men than women. In men, type II muscle fibers are usually larger than type I fibers, whereas the opposite is true in women.

The decline in muscle mass, most prominent in the lower limbs, is accompanied by a $30 \%$ to $40 \%$ decrease in muscle fiber number between the second and eight decade [25]. Further evidence has suggested that apoptosis may play a considerable role in mediating the progression of muscle fiber loss in aging [26]. Mitochondrialmediated apoptosis has been postulated as one of the mechanisms associated with muscle fiber loss. Muscle fiber size is also affected but to a lesser extent. The reduction in muscle fiber size is fiber type specific, with $10 \%-40 \%$ smaller type II fibers observed in muscle tissue collected from elderly compared with young controls [27]. In contrast, type I muscle fiber size is largely unaffected $[22,28,29]$. These fiber type specific changes can be explained by the age-related remodeling of motor units that result mostly in denervation of type II muscle fibers with collateral re-innervation of type I muscle fibers [30-32].

A reduction in whole muscle and individual fiber size is a contributor to sarcopenia but may not be the most important explanation for it. Changes in muscle fiber quality (force corrected for size) have been reported by several investigators $[15,27,30,31]$. In other words, loss of muscle strength and power with aging can in part be explained by reductions in intrinsic force-generating capacity of skeletal muscle fibers [32-36]. For example, Russ et al. [34] showed that older skeletal muscle exhibits a $34 \%$ reduction in its intrinsic force-generating capacity. The mechanism underlying this reduction includes agerelated alterations in cellular and molecular processes such as changes in the satellite cell population, excitation-contraction coupling, myofilament interaction, mitochondrial function, and adipocyte infiltration $[37,38]$ (see below).

\section{Fiber type transformation}

Muscle fiber type composition can change in response to various external stimuli in a fiber type-specific fashion. For example, type I fibers are more susceptible to inactivity and denervation-induced atrophy, while type II fibers are more affected with cancer, diabetes, chronic heart failure, and aging [39]. This difference in susceptibility can be explained by the activation and response to different signaling pathways. For example the peroxisome proliferator-activated receptor gamma coactivator 1-alpha $(\mathrm{PGC} 1 \alpha)$ protects type I fibers from atrophy while the transforming growth factor beta (TGF $\beta$ ) family and the nuclear factor kappaB (NF-kB) predominantly affect type IIx fibers [39]. Aging is associated with a fast-to-slow fiber type shift, affecting mostly IIx fibers. As mentioned above, these muscle fiber changes are associated with age-dependent changes in motor unit composition [40].

\section{Excitation-contraction coupling}

Excitation-contraction coupling is a physiological process that converts the sarcolemmal action potential into muscle action and force generation. One of the key elements of this process are the dihydropyridine receptors located in the transverse tubule which are needed to activate calcium release from the sarcoplasmic reticulum through the ryanodine receptor. Once calcium is released into the myoplasm, it binds to troponin $\mathrm{C}$ and-through interactions with troponin I and $\mathrm{T}$ along with tropomyosin-results in actomyosin interaction. Calcium is then pumped back into the sarcoplasmic reticulum or competitively bound. Disruption or uncoupling at any step of this process may result in reduced muscle fiber activation, force generation, and lower whole muscle strength [41].

Aging causes a reduction in the number of dihydropyridine receptors, uncoupling between these receptors and the ryanodine receptors, and deficits in calcium release $[37,38]$. One mechanism to explain this sequence of events is the reduction in the expression of the sarcoplasmic reticulum junctional-face membrane (JP-45) [42] that alters the levels of specific dihydropyridine receptor 
subunits $[38,42]$ interfering with the protein-protein interactions involved in excitation-contraction coupling [34].

\section{Myofilament aging}

The importance of age-related changes at the level of the myofilaments has been recently discussed [43]. The majority of studies demonstrate that older men and women have reduced single fiber maximal force even after adjustments for variability in fiber size. This is true in both type I and II fibers. Many molecular mechanisms have been proposed to explain such dysfunction including a reduction in myosin protein content; this may be particularly true in immobilized muscle [32]. The latter may be related to gene transcription with abnormalities in the myostatin gene and/or reduction in translation and protein synthesis leading to a lower myosin concentration per unit of muscle cell area. In addition, posttranslational modifications of myosin via mechanisms such as oxidation and glycosylation may be present. Oxidative modification of myosin may disrupt the binding of the myosin head to the actin filament and, thus, reduce the number of actin-myosin cross-bridges in the strongbinding state [44]. This will limit force and power generation. Other than receptor changes, structural alterations of myosin causing a change in the kinetics of the crossbridge cycle, has been suggested to contribute to ageassociated muscle weakness [45]. It is interesting that longitudinal studies suggest that clusters of fibers that are not lost during aging try to compensate for these agerelated differences in fiber size and quality $[18,46,47]$ and although whole muscle performance is reduced, single muscle fiber properties may be relatively well preserved.

Other mechanical properties are also altered in older human. An increased in instantaneous stiffness (reduction in elasticity) has been reported in whole muscle as well as in single fibers [33]. This may be due to an increase in the number of cross-bridges in the weak-binding state but other factors such as changes in cross-bridge compliance and sarcomeric elements like titin may contribute. As previously noted, the role of this important protein in muscle actions has been recently reviewed [48]. In conclusion, independent of the mechanism(s) limiting normal myofilament interaction, substantial evidence supports the idea that muscle impairment in older people is, at least partially, a functional and not a quantita- tive problem.

\section{Adipocyte infiltration}

Aging is associated with increases in both intra- and inter-muscular adipose tissue and it has been showed that increased muscle fat content is associated with reduced muscle strength $[49,50]$. However, a direct relationship between increased intermuscular fat and age-related muscle weakness has not been established [51]. One of the potential mechanisms explaining how fat tissue decreases muscle force is the increased tumor necrosis factor alpha (TNF- $\alpha$ ) production. It can be suggested that TNF- $\alpha$ may act directly on muscle fibers disrupting excitation-contraction coupling by altering intracellular calcium stores. This has been demonstrated to be the case in cardiac myocytes [52].

\section{Mitochondrial function}

Another example of the age-related alterations in muscle cell organelles is the loss of mitochondrial content and function [53]. Mitochondria respond to multitude of intracellular signals by modulating their function: ATP production, reactive oxygen species (ROS) production, and sensitivity to permeability transition. In aging muscle, the question is whether alterations in mitochondria represent a primary organelle defect versus a secondary (potentially adaptive) response to a changing cellular environment. Sensitization to permeability transition and release of mitochondrial-derived proapoptotic factors seems to be a constant finding in aging muscle regardless of the level of physical activity [54]. There are two possible mechanisms underlying these intrinsic mitochondrial changes: 1) mitochondrial genome damage that accumulates over the years and leads to impaired synthesis of mitochondria or synthesis of mitochondria with impaired function [55] and 2) disruption of mitochondrial turnover-mitochondrial removal and replacementwhich results in accumulation of damaged mitochondria with impaired function [56]. Apart from this intrinsic alteration in mitochondrial function, extrinsic factors known as 'aging milieu' including oxidative stress and muscle fiber denervation may play a very important role in mitochondrial dysfunction [54]. It is interesting to note that the loss in mitochondrial function can be partially reversed by exercise training [57]. This is supported by the higher levels of oxidative enzyme and of molecular 
targets associated with mitochondrial biogenesis seen in endurance octogenarian athletes.

\section{CONCLUSION}

\section{Clinical implications of muscle fiber aging}

Sarcopenia is considered by many investigators, clinicians, and public health experts as an emerging threat because it leads to a loss of functional capacity, mobility, and independence. As a result, much research has focused on interventions to slow down or reverse sarcopenia in elderly. Abundant scientific evidence supports an important role for physical exercise in the prevention and rehabilitation of age-related functional decline and development of disability. However, a better understanding of the cellular changes associated with sarcopenia is needed before more specific interventions can be designed. In this brief review we have considered the evidence showing important intrinsic changes at the level of single muscle fibers that result in muscle weakness and atrophy in elderly.

In summary, age-related muscle changes are very complex and involve multiple features and mechanisms influenced both by intrinsic and extrinsic/environmental conditions. These muscle changes may look quite different than those associated with injuries, chronic diseases, and immobilization, so the therapeutic approach must be tailored to the individual case considering the changes at the muscle cell level. In order to prevent and treat sarcopenia effectively, future research is needed to elucidate where the targeted area at the muscle fiber level is for each individual.

\section{CONFLICT OF INTEREST}

No potential conflict of interest relevant to this article was reported.

\section{REFERENCES}

1. World Health Organization [Internet]. Geneva: World Health Organization; c2015 [cited 2015 Feb 16]. Available from: http://www.who.int/.

2. Countryeconomy.com [Internet]. [place unknown]: Countryeconomy.com; c2015 [cited 2015 Feb 16]. Available from: http://countryeconomy.com/.
3. Brady AO, Straight CR, Evans EM. Body composition, muscle capacity, and physical function in older adults: an integrated conceptual model. J Aging Phys Act 2014;22:441-52.

4. Gill TM, Allore HG, Hardy SE, Guo Z. The dynamic nature of mobility disability in older persons. J Am Geriatr Soc 2006;54:248-54.

5. Gill TM, Kurland B. The burden and patterns of disability in activities of daily living among communityliving older persons. J Gerontol A Biol Sci Med Sci 2003;58:70-5.

6. Hardy SE, Dubin JA, Holford TR, Gill TM. Transitions between states of disability and independence among older persons. Am J Epidemiol 2005;161:575-84.

7. Hardy SE, Gill TM. Recovery from disability among community-dwelling older persons. JAMA 2004;291: 1596-602.

8. Manini TM, Visser M, Won-Park S, Patel KV, Strotmeyer ES, Chen $\mathrm{H}$, et al. Knee extension strength cutpoints for maintaining mobility. J Am Geriatr Soc 2007;55:451-7.

9. Manini T. Development of physical disability in older adults. Curr Aging Sci 2011;4:184-91.

10. Rosenberg IH. Summary comments. Am J Clin Nutr 1989;50:1231-3.

11. Rosenberg IH. Sarcopenia: origins and clinical relevance. J Nutr 1997;127(5 Suppl):990S-991S.

12. Cruz-Jentoft AJ, Baeyens JP, Bauer JM, Boirie Y, Cederholm T, Landi F, et al. Sarcopenia: European consensus on definition and diagnosis: report of the European Working Group on sarcopenia in older people. Age Ageing 2010;39:412-23.

13. Studenski SA, Peters KW, Alley DE, Cawthon PM, McLean RR, Harris TB, et al. The FNIH sarcopenia project: rationale, study description, conference recommendations, and final estimates. J Gerontol A Biol Sci Med Sci 2014;69:547-58.

14. Ryu M, Jo J, Lee Y, Chung YS, Kim KM, Baek WC. Association of physical activity with sarcopenia and sarcopenic obesity in community-dwelling older adults: the Fourth Korea National Health and Nutrition Examination Survey. Age Ageing 2013;42:734-40.

15. Frontera WR, Hughes VA, Fielding RA, Fiatarone MA, Evans WJ, Roubenoff R. Aging of skeletal muscle: a 12yr longitudinal study. J Appl Physiol 2000;88:1321-6. 16. Yamada M, Moriguch Y, Mitani T, Aoyama T, Arai H. 
Age-dependent changes in skeletal muscle mass and visceral fat area in Japanese adults from 40 to 79 yearsof-age. Geriatr Gerontol Int 2014;14 Suppl 1:8-14.

17. Hughes VA, Frontera WR, Wood M, Evans WJ, Dallal GE, Roubenoff R, et al. Longitudinal muscle strength changes in older adults: influence of muscle mass, physical activity, and health. J Gerontol A Biol Sci Med Sci 2001;56:B209-17.

18. Reid KF, Pasha E, Doros G, Clark DJ, Patten C, Phillips EM, et al. Longitudinal decline of lower extremity muscle power in healthy and mobility-limited older adults: influence of muscle mass, strength, composition, neuromuscular activation and single fiber contractile properties. Eur J Appl Physiol 2014;114:29-39.

19. Cheung TH, Rando TA. Molecular regulation of stem cell quiescence. Nat Rev Mol Cell Biol 2013;14:329-40.

20. Yin H, Price F, Rudnicki MA. Satellite cells and the muscle stem cell niche. Physiol Rev 2013;93:23-67.

21. Shefer G, Van de Mark DP, Richardson JB, YablonkaReuveni Z. Satellite-cell pool size does matter: defining the myogenic potency of aging skeletal muscle. Dev Biol 2006;294:50-66.

22. Verdijk LB, Koopman R, Schaart G, Meijer K, Savelberg HH, van Loon LJ. Satellite cell content is specifically reduced in type II skeletal muscle fibers in the elderly. Am J Physiol Endocrinol Metab 2007;292:E1517.

23. McKay BR, Ogborn DI, Baker JM, Toth KG, Tarnopolsky MA, Parise G. Elevated SOCS3 and altered IL-6 signaling is associated with age-related human muscle stem cell dysfunction. Am J Physiol Cell Physiol 2013;304:C717-28.

24. Dumitru D, Amato AA, Zwarts MJ. Electrodiagnostic medicine. 2nd ed. Philadelphia: Hanley \& Belfus Inc.; 2002.

25. Lexell J. Human aging, muscle mass, and fiber type composition. J Gerontol A Biol Sci Med Sci 1995;50 Spec No:11-6.

26. Dirks A, Leeuwenburgh C. Apoptosis in skeletal muscle with aging. Am J Physiol Regul Integr Comp Physiol 2002;282:R519-27.

27. Frontera WR, Suh D, Krivickas LS, Hughes VA, Goldstein R, Roubenoff R. Skeletal muscle fiber quality in older men and women. Am J Physiol Cell Physiol 2000;279:C611-8.

28. Janssen I, Heymsfield SB, Wang ZM, Ross R. Skeletal muscle mass and distribution in 468 men and women aged 18-88 yr. J Appl Physiol (1985) 2000;89:81-8.

29. Clark BC, Taylor JL. Age-related changes in motor cortical properties and voluntary activation of skeletal muscle. Curr Aging Sci 2011;4:192-9.

30. Delbono O. Expression and regulation of excitationcontraction coupling proteins in aging skeletal muscle. Curr Aging Sci 2011;4:248-59.

31. Kostek MC, Delmonico MJ. Age-related changes in adult muscle morphology. Curr Aging Sci 2011;4:22133.

32. D'Antona G, Pellegrino MA, Adami R, Rossi R, Carlizzi $\mathrm{CN}$, Canepari M, et al. The effect of ageing and immobilization on structure and function of human skeletal muscle fibres. J Physiol 2003;552(Pt 2):499-511.

33. Ochala J, Frontera WR, Dorer DJ, Van Hoecke J, Krivickas LS. Single skeletal muscle fiber elastic and contractile characteristics in young and older men. J Gerontol A Biol Sci Med Sci 2007;62:375-81.

34. Russ DW, Grandy JS, Toma K, Ward CW. Ageing, but not yet senescent, rats exhibit reduced muscle quality and sarcoplasmic reticulum function. Acta Physiol (Oxf) 2011;201:391-403.

35. Yu F, Hedstrom M, Cristea A, Dalen N, Larsson L. Effects of ageing and gender on contractile properties in human skeletal muscle and single fibres. Acta Physiol (Oxf) 2007;190:229-41.

36. D'Antona G, Pellegrino MA, Carlizzi CN, Bottinelli R. Deterioration of contractile properties of muscle fibres in elderly subjects is modulated by the level of physical activity. Eur J Appl Physiol 2007;100:603-11.

37. Delbono O. Regulation of excitation contraction coupling by insulin-like growth factor- 1 in aging skeletal muscle. J Nutr Health Aging 2000;4:162-4.

38. Renganathan M, Messi ML, Delbono O. Dihydropyridine receptor-ryanodine receptor uncoupling in aged skeletal muscle. J Membr Biol 1997;157:247-53.

39. Wang Y, Pessin JE. Mechanisms for fiber-type specificity of skeletal muscle atrophy. Curr Opin Clin Nutr Metab Care 2013;16:243-50.

40. Ciciliot S, Rossi AC, Dyar KA, Blaauw B, Schiaffino S. Muscle type and fiber type specificity in muscle wasting. Int J Biochem Cell Biol. 2013;45:2191-9.

41. Manini TM, Clark BC. Dynapenia and aging: an update. J Gerontol A Biol Sci Med Sci 2012;67:28-40.

42. Anderson AA, Altafaj X, Zheng Z, Wang ZM, Delbono 
$\mathrm{O}$, Ronjat M, et al. The junctional SR protein JP-45 affects the functional expression of the voltage-dependent Ca2+ channel Cav1.1. J Cell Sci 2006;119(Pt 10):2145-55.

43. Miller MS, Toth MJ. Myofilament protein alterations promote physical disability in aging and disease. Exerc Sport Sci Rev 2013;41:93-9.

44. Moen RJ, Klein JC, Thomas DD. Electron paramagnetic resonance resolves effects of oxidative stress on muscle proteins. Exerc Sport Sci Rev 2014;42:30-6.

45. Lowe DA, Thomas DD, Thompson LV. Force generation, but not myosin ATPase activity, declines with age in rat muscle fibers. Am J Physiol Cell Physiol 2002;283:C187-92.

46. Frontera WR, Reid KF, Phillips EM, Krivickas LS, Hughes VA, Roubenoff R, et al. Muscle fiber size and function in elderly humans: a longitudinal study. J Appl Physiol (1985) 2008;105:637-42.

47. Reid KF, Doros G, Clark DJ, Patten C, Carabello RJ, Cloutier GJ, et al. Muscle power failure in mobilitylimited older adults: preserved single fiber function despite lower whole muscle size, quality and rate of neuromuscular activation. Eur J Appl Physiol 2012; 112:2289-301.

48. Monroy JA, Powers KL, Gilmore LA, Uyeno TA, Lindstedt SL, Nishikawa KC. What is the role of titin in active muscle? Exerc Sport Sci Rev 2012;40:73-8.

49. Goodpaster BH, Carlson CL, Visser M, Kelley DE, Scherzinger A, Harris TB, et al. Attenuation of skeletal muscle and strength in the elderly: the Health ABC Study. J Appl Physiol (1985) 2001;90:2157-65.

50. Goodpaster BH, Kelley DE, Thaete FL, He J, Ross R.
Skeletal muscle attenuation determined by computed tomography is associated with skeletal muscle lipid content. J Appl Physiol (1985) 2000;89:104-10.

51. Delmonico MJ, Harris TB, Visser M, Park SW, Conroy MB, Velasquez-Mieyer P, et al. Longitudinal study of muscle strength, quality, and adipose tissue infiltration. Am J Clin Nutr 2009;90:1579-85.

52. Reid MB, Lannergren J, Westerblad H. Respiratory and limb muscle weakness induced by tumor necrosis factor-alpha: involvement of muscle myofilaments. Am J Respir Crit Care Med 2002;166:479-84.

53. Broskey NT, Greggio C, Boss A, Boutant M, Dwyer A, Schlueter L, et al. Skeletal muscle mitochondria in the elderly: effects of physical fitness and exercise training. J Clin Endocrinol Metab 2014;99:1852-61.

54. Hepple RT. Mitochondrial involvement and impact in aging skeletal muscle. Front Aging Neurosci 2014; 6:211.

55. Hiona A, Leeuwenburgh C. The role of mitochondrial DNA mutations in aging and sarcopenia: implications for the mitochondrial vicious cycle theory of aging. Exp Gerontol 2008;43:24-33.

56. Joseph AM, Adhihetty PJ, Wawrzyniak NR, Wohlgemuth SE, Picca A, Kujoth GC, et al. Dysregulation of mitochondrial quality control processes contribute to sarcopenia in a mouse model of premature aging. PLoS One 2013;8:e69327.

57. Trappe S, Hayes E, Galpin A, Kaminsky L, Jemiolo B, Fink W, et al. New records in aerobic power among octogenarian lifelong endurance athletes. J Appl Physiol (1985) 2013;114:3-10. 